\title{
Micro-osteoperforations and Its Effect on the Rate of Tooth Movement: A Systematic Review
}

\author{
Khalifa S. Al-Khalifa' Hosam A. Baeshen² \\ 1Department of Preventive Dental Sciences, College of Dentistry, \\ Imam Abdulrahman Bin Faisal University, Dammam, Saudi Arabia \\ ${ }^{2}$ Department of Orthodontics, College of Dentistry, King Abdulaziz \\ University, Jeddah, Saudi Arabia
}

\begin{abstract}
Address for correspondence Khalifa S. Al-Khalifa, BDS, MPH, MHSA, DrPH, College of Dentistry, Imam Abdulrahman Bin Faisal University, P.O. Box 1982, Dammam 31441, Saudi Arabia (e-mail: kalkhalifa@iau.edu.sa).
\end{abstract}

Eur J Dent:2021;5:158-167

\author{
Abstract \\ Keywords \\ - orthodontic \\ - tooth movement \\ - accelerated tooth \\ movement \\ - micro- \\ osteoperforation \\ - and regional \\ acceleratory \\ phenomenon
}

Prolonged orthodontic treatments have inconvenienced patients and clinicians alike. Surgically assisted techniques for accelerating orthodontic tooth movement have shown promising results in the literature over the years. The minimally invasive nature of micro-osteoperforations (MOPs), however, for enhanced orthodontic tooth movement has recently gained momentum, with many clinical trials conducted on both animals and humans. An electronic search was performed to extract papers using PubMed, Google Scholar, Scopus, and Web of Science. The keywords that were used included "MOP," "accelerating tooth movement," "orthodontic tooth movement," and "regional acceleratory phenomenon." The studies that met our inclusion criteria were extracted and evaluated in this review. MOPs have been proven time and again, in animal and human studies alike, to increase the rate of orthodontic tooth movement. The application of perforations to cortical bone present in the pathway of teeth, which are specifically to be moved creates transient osteopenia. This reduces the density of the cortical bone, hence speeding up the rate of orthodontic tooth movement. Many techniques have been implemented and perfected to enhance orthodontic tooth movement and shorten the treatment time in the literature. MOPs have proven to be a universally applied, nontechnical, repeatable, and minimally invasive method of accelerating tooth movement, with extremely minimal consequences.

\section{Introduction}

It is a common complaint among patients undergoing orthodontic treatment of the exhaustive time undertaken till completion, reaching an average of 2 or more years. ${ }^{1-3}$ Orthodontic treatment is not a 1-day or 30-minute treatment like other disciplines of dentistry. In orthodontic treatment, patient goes through with craniofacial rehabilitation and it takes months or years. This prolonged treatment also results in various complications for teeth as well as the associated tooth-supporting structures. The most commonly reported are white spot lesions and dental caries, ${ }^{4}$ orthodontically induced apical root resorption, ${ }^{5}$ poor oral hygiene leading to gingivitis and periodontitis, ${ }^{3}$ and an excessive decrease in patient compliance. ${ }^{6}$

Orthodontic tooth movement is considered primarily as a "periodontal phenomenon,"7 understandably because of the notable compression of periodontal ligaments, in turn causing turnover of alveolar bone. H.M.F. in 1983, however, recognized and put forth the idea of "regional acceleratory phenomenon" (RAP), stressing over the fact that there occurred a decline in regional bone density or osteopenia without any comprehensive decrease in bone volume. ${ }^{8}$ This, in turn, accelerated tooth movement through the surrounding jaw bone.
Dol https://doi.org/ $10.1055 / \mathrm{s}-0040-1713955$ ISSN 1305-7456. (c) 2020. European Journal of Dentistry.

This is an open access article published by Thieme under the terms of the Creative Commons Attribution-NonDerivative-NonCommercial-License, permitting copying and reproduction so long as the original work is given appropriate credit. Contents may not be used for commercial purposes, or adapted, remixed, transformed or built upon. (https://creativecommons.org/licenses/by-nc-nd/4.0/) Thieme Medical and Scientific Publishers Pvt. Ltd., A-12, 2nd Floor, Sector 2, Noida-201301 UP, India 


\section{Biologic Explanation of Tooth Movement in Orthodontics}

The amount and rate of tooth movement are entirely dependent upon the biological response to applied orthodontic forces. The average rate of tooth movement by conventional orthodontics is estimated to be around 0.8 to $1.2 \mathrm{~mm} / \mathrm{month}$ when continued forces are being applied. ${ }^{9}$ The rate of tooth movement depends on the amount of bone turnover. Thus, the osteoclastic activity occurs at the site of periodontal ligament compression. Inflammatory markers, cytokines and chemokines, circulating within the blood have been found to increase in response to the application of orthodontic forces on teeth. ${ }^{10,11}$

The areas of compression and tension at the periodontal ligament sites cause the blood vessels there to constrict. This results in an initial release of chemokines and cytokines from the locally surrounding fibroblasts, osteoblasts, and the endothelial cells of blood vessels involved. These chemokines and cytokines, when released, act as pro-inflammatory mediators enhancing the inflammatory effects of the osteoclast precursors circulating within the bloodstream. ${ }^{12,13}$ These activated osteoclast precursors result in differentiating into multinucleated giant cells that then proceed onward to resorb the alveolar bone ensuing with the much needed orthodontic tooth movement. ${ }^{12,14}$ Side by side, the anti-inflammatory responses to the release of pro-inflammatory cytokines is imperative to maintain a balance, thus preventing the destructive effects of the ongoing osteolysis. Ratelimiting factors in orthodontic tooth movement, first and foremost, tends to be the amount of bone turnover and the bone density surrounding the teeth to be moved. ${ }^{15}$

Hence, to know thoroughly about pro-inflammatory and anti-inflammatory responses of the periodontium and the circulating inflammatory cells to orthodontic forces is of utmost importance so that there is the continued development of safe therapies to shorten orthodontic treatment time. ${ }^{14}$

\section{Various Techniques for Accelerating Tooth Movement: Summary}

The advent of fixed orthodontics brought with it the challenge of reducing the overall treatment time for clinicians and researchers alike. Over the years, many methods for accelerating tooth movement have been brought to the limelight, including mechanical, chemical as well as pharmacologic, along with surgically assisted techniques. ${ }^{12,16}$ Mechanical or physical methods for accelerating tooth movement include, but not limited to regional stimulations by low-dose laser application, ${ }^{17}$ passing direct electric currents, ${ }^{5}$ and equipment-assisted ultrasonic or resonance vibrations. ${ }^{12,18}$

Chemical stimulations, both local and systemic, have also been used to facilitate the orthodontic treatment process. ${ }^{12}$ Injections of cell mediators acting locally including those of prostaglandins, leukotrienes, thromboxanes, corticosteroids, diazepam, and vasomotor medicines. ${ }^{12,19}$ However, certain chemical medications-when applied-have undeniable systemic effects on patients, thereby negating the primary impact of just safely accelerating orthodontic tooth movement. Among these techniques, the one that showed the most promising results in the amount of tooth movement in a given time were the surgically assisted methods for moving teeth. They are believed to have shown the most positive effects on the rate of orthodontic tooth movement. ${ }^{20,21} \mathrm{~A}$ wide array of surgical assisted orthodontic tooth movement accelerating techniques have been explored as reported in the literature. Many of them are invasive and collectively costly, in addition to the orthodontic treatment itself.

Surgically assisted techniques were first pioneered in the orthodontic literature by Köle, ${ }^{22}$ where he believed that the cortical layer of bone provided the primary sources of resistance to tooth movement. Hence, creating injuries in the bone, or osteotomies and corticotomies, could provide the necessary physical stimulant for activating the RAP, decreasing bone density, increasing bone turnover, and consequently tooth movement. This was termed as the "bony block movements" of individual teeth where vertical corticotomies were applied between two adjacent teeth only through the cortical bone. These were followed by subapical horizontal osteotomies penetrating through the full thickness of the alveolar bone, creating bone segments or blocks containing the teeth to be moved.

Suya et $\mathrm{al}^{23}$ then followed through with the same technique as Köle, ${ }^{22}$ modifying the full thickness horizontal osteotomy to just weakening the cortical layer of the alveolar bone or subapical corticotomy, with an added advantage of better chances of preserving tooth vitality and subsequent reduction in orthodontic treatment time. Then in 2008, Wilcko et $\mathrm{al}^{24}$ came forward with the idea of "periodontally accelerated osteogenic orthodontics." They introduced the use of alveolar bone grafting in addition to corticotomy-assisted procedures put forth by Köle, ${ }^{22}$ refuting that due to orthodontic tooth movement chances of dehiscence, fenestrations, thinning of cortical bone, and relapse is a significant risk. This resulted in the treatment duration being shortened almost three to four times than the conventional orthodontic treatment period, notwithstanding the increased cost with an added surgical procedure during the treatment period.

Trying to curb the invasiveness of the surgically assisted techniques being used to accelerate tooth movement, Park et $\mathrm{a}^{25}$ introduced the procedure of corticision as an alternative to the corticotomies. This strategy entailed placing cortical incisions without the need of raising soft tissue flaps. Even though treatment durations were reported to be completed in a short period of 10 months, acceptability among patients was low.

Moreover, Dibart and Keser $^{26}$ presented a minimally invasive technique called piezocision, which entailed a flapless method of using a piezosaw and administering piezoincisions of a length and depth of $3 \mathrm{~mm}$ in the area of tooth movement. This method also facilitated the use of hard or soft tissue grafting through the tunnel method. However, no significant results were reported in terms of accelerated tooth movement in the literature by the use of this method. ${ }^{12,27}$ 


\section{Methodology}

\section{Search Strategy}

An electronic search was conducted to extract papers from MedLine via PubMed, Google Scholar, Scopus, and Web of Science using the keywords; "MOP," "accelerating tooth movement," "orthodontic tooth movement," and "regional acceleratory phenomenon" in combination. Original research articles reported in the English language available on the search engines were scrutinized and included in this narrative review.

\section{Inclusion Criteria}

The following inclusion criteria were followed for this review: (1) studies using MOPs to accelerate orthodontic tooth movement, (2) animal studies, (3) human trials, (4) articles reported in the English language, and (5) free full articles. All these included articles used in the formation of the - Tables 1 and 2.

\section{Exclusion Criteria}

The following exclusion criteria were followed for this review: (1) other than English language, (2) commentary, and (3) letters to the editor.

\section{Micro-osteoperforations: Literature Search}

Among the various surgical-assisted techniques that have been used over the years, micro-osteoperforations (MOPs) is a relatively newer method being used to induce and stimulate alveolar bone turnover. Added to that the advantage of this technique is minimally invasive on the surrounding structures as no flap is raised and no cuts made in the cortical bone to facilitate bony block movement. ${ }^{38}$ Tooth movement is primarily a "periodontal phenomenon," of an aseptic inflammation in response to orthodontic forces leading to enhanced infiltration of leucocytes. This generates a continuous loop with positive feedback mechanism courtesy chemokines and cytokines being released by the native and newly derived osteoblasts and fibroblasts in the vicinity ${ }^{15}$ Statistically significant levels of certain chemokines and cytokines have been found in the gingival crevicular fluid samples obtained ${ }^{11}$ including those of interleukin $1-\alpha(\mathrm{IL}-1 \alpha)$, IL-1 $\beta$, tumor necrosis factor- $\alpha$, IL-6, IL-8, osteoclast differentiation factor, CCL-2, CCL-3, and CCL-5. ${ }^{11,28}$

Furthermore, the release of these chemokines and cytokines responds with enhanced bone turnover in the compressed and tensed periodontal ligament induced by orthodontic forces ${ }^{8}$ with transient osteopenia in the region, minimizing the resistance to tooth movement. Thus, the rate of tooth movement is dependent on the amount of bone resorption occurring, which is in control of the osteoclast activity within those sites. ${ }^{12,39}$ In the literature, an animal study ${ }^{28}$ and a human clinical trial ${ }^{11}$ have evaluated the levels of cytokines and chemokines in the gingival crevicular/salivary fluid samples.

In contrast, MOPs are relatively safe to administer, requiring no specialized training and can be done using commonly available instruments and orthodontic appliances within the orthodontists' clinic. They are a relatively new procedure, which can be used to accelerate tooth movement requiring extremely minimal interventions surgically, with no soft tissue flaps raised. MOPs are indicated to be used without any harm on various corrective procedures done orthodontically, inclusive but not limited to molar uprighting, space closure, aligning crowded mandibular anterior teeth, canine impactions, etc. ${ }^{38}$

As with all procedures, MOP administration requires a proper protocol to be followed. A comprehensive medical and dental history is imperative as the application of local anesthesia before the process involves a history of any comorbid or allergies that could put the patient's life in danger. Informed consent is crucial, with the procedure being explained to the patient to minimize anxiety and give a clear understanding with regards to the point of using MOPs and the various consequences. An orthopantomogram or conebeam computed tomography can be used to provide initial images and records of the jaw bone and surrounding vital structures impeding the administration of the perforations and their proper placement. Evaluations of the quality of surrounding bone, location of the sinus, the roots of the teeth, and the inferior alveolar nerve are pivotal for the clinician to know to place the proper number of MOPs at the appropriately decided location within the jaw bone. The aseptic inflammatory response to the MOPs can vary with regards to the number of perforations administered in addition to their depth as well..$^{40}$

Various other tools have been used to place perforations as apparent in the literature, ${ }^{9,29,35,36}$ for example, mini-implant facilitated perforations and round burs. A disposable device was explicitly designed by PROPEL Orthodontics (Ossining, NY) to deliver perforations. ${ }^{3,11,37}$ It has a manually adjustable tool with varying lengths of 3,5 , and $7 \mathrm{~mm}$ for the corresponding depth of the perforation decided. ${ }^{12}$ Postoperative care after the minor surgical procedure requires no pain medications usually. Still, as each individual is unique, intake of acetaminophen is recommended as opposed to nonsteroidal anti-inflammatory drugs (NSAIDs) because of their inhibitory mechanism of action on the inflammatory effect of MOPs, negating the whole procedure if taken. ${ }^{40}$ In - Table 1, details of all animal studies reported on the MOPs.

Research on MOPs commenced in 2010 with a splitmouth animal study conducted by Teixeira et a ${ }^{28}$ on 48 adult rats. These rats were divided into four groups of 12: one with solely orthodontic force applied, one with orthodontic force with soft tissue flap raised, one withsoft tissue flap along with three shallow perforations of $0.25 \mathrm{~mm}$ diameter on the buccal cortical plate using a handpiece and a round bur and orthodontic force. The last group served as a control. A significantly increased expression of cytokines and chemokines was observed in the group of rats that were given shallow perforations in the cortical bone, compared with the other groups. Out of a total of 92 cytokine/cytokine receptors that were evaluated, 37 of them were significantly increased in the experimental groups as compared with the control. A total of eight cytokines showed a 1.6- to 2.7-fold increase, 
Table 1 Details of animal studies that were conducted with implementation of micro-osteoperforations included in the review

\begin{tabular}{|c|c|c|c|c|c|}
\hline Study (y) & $\begin{array}{l}\text { Specimen/ } \\
\text { study type }\end{array}$ & $\begin{array}{l}\text { Sample size/ } \\
\text { age range }\end{array}$ & $\begin{array}{l}\text { Mops delivered details/MOP } \\
\text { device used }\end{array}$ & $\begin{array}{l}\text { Duration } \\
\text { of study }\end{array}$ & Tooth movement results \\
\hline $\begin{array}{l}\text { Teixeira et } \mathrm{al}^{28} \\
(2010)\end{array}$ & $\begin{array}{l}\text { Animal } \\
\text { Split-mouth } \\
\text { study }\end{array}$ & $\begin{array}{l}48 \text { adult male } \\
\text { Sprague-Dawley } \\
\text { rats } \\
\text { Age: } 120 \mathrm{~d}\end{array}$ & $\begin{array}{l}\text { Number: } 3 \text { shallow perforations } \\
\text { Location: mesial to the first maxil- } \\
\text { lary molar in the OFP group } \\
\text { Device: handpiece with round bur }\end{array}$ & $28 d$ & $\begin{array}{l}\text { Average tooth movement } \\
\text { in the } \mathrm{O} \text { and OF groups was } \\
0.29 \mathrm{~mm} \text {, which was } \\
\text { significantly different than } \\
\text { the control group } \\
\text { Average tooth movement in } \\
\text { the OFP group was } 0.62 \mathrm{~mm} \text {, } \\
\text { significantly higher when } \\
\text { compared with the O, OF, } \\
\text { and C groups }\end{array}$ \\
\hline $\begin{array}{l}\text { Cheung et al }{ }^{29} \\
(2016)\end{array}$ & $\begin{array}{l}\text { Animal } \\
\text { Split-mouth } \\
\text { study }\end{array}$ & $\begin{array}{l}6 \text { male Sprague- } \\
\text { Dawley rats }\end{array}$ & $\begin{array}{l}\text { Number: } 5 \text { MOPs } \\
\text { Location: MOPs were placed } 1 \text { to } \\
3 \text { mm apart, mesially and palatally } \\
\text { placed to left maxillary molar } \\
\text { Device: automated mini-implant } \\
\text { driver } \\
\text { Details: } 1.2 \mathrm{~mm} \text { diameter, } 1 \mathrm{~mm} \\
\text { depth }\end{array}$ & 21 days & $\begin{array}{l}\text { Tooth movement was signif- } \\
\text { icantly greater at MOP side } \\
(0.54 \pm 0.13 \mathrm{~mm}) \text { than } \\
\text { control side }(0.29 \pm \\
0.15 \mathrm{~mm}) \\
\text { Maximum first M moved } \\
\text { almost twofold times more } \\
\text { on the side where MOPs } \\
\text { were administered }\end{array}$ \\
\hline $\begin{array}{l}\text { Sugimori et } \mathrm{al}^{9} \\
(2010)\end{array}$ & Animal study & $\begin{array}{l}50 \text { male Wistar } \\
\text { rats } \\
\text { Randomly } \\
\text { assigned to two } \\
\text { groups by simple } \\
\text { randomization }\end{array}$ & $\begin{array}{l}\text { Number: } 3 \mathrm{MOPs} \\
\text { Location: buccal alveolar bone } \\
\text { mesial to the left maxillary first } \\
\text { molar } \\
\text { Device: handpiece with round bur } \\
\text { Details: diameter and depth were } \\
0.25 \pm 0.005 \mathrm{~mm} \text {. }\end{array}$ & $14 d$ & $\begin{array}{l}\text { Tooth movement in } \\
\text { experimental group signifi- } \\
\text { cantly greater on days } 4 \text { to } \\
14 \text { than in the control group }\end{array}$ \\
\hline $\begin{array}{l}\text { Cramer et } \mathrm{al}^{3} \\
(2010)\end{array}$ & Animal study & $\begin{array}{l}7 \text { mature male } \\
\text { beagle dogs } \\
\text { Average age } \\
24 \text { mo }\end{array}$ & $\begin{array}{l}\text { Number: } 8 \mathrm{MOPs} \\
\text { Location: } 2 \text { performed in the } \\
\text { furcation area of maxillary second } \\
\text { premolar, } 6 \text { performed distal to } \\
\text { maxillary second molar } \\
\text { Device: Propel device } \\
\text { Details: } 7 \text { mm depth }\end{array}$ & 7 wks & $\begin{array}{l}\text { Teeth on experimental side } \\
\text { moved only on an average } \\
\text { range } 0.05 \text { to } 0.27 \text { mm more } \\
\text { than teeth on control side, } \\
\text { which was not statistically } \\
\text { significant }\end{array}$ \\
\hline $\begin{array}{l}\text { Gemert et } \mathrm{al}^{4} \\
\text { (2019) }\end{array}$ & $\begin{array}{l}\text { Animal study } \\
\text { Split-mouth } \\
\text { study }\end{array}$ & $\begin{array}{l}13 \text { mature male } \\
\text { beagle dogs } \\
\text { Average age } 2 \text { y }\end{array}$ & $\begin{array}{l}\text { Number: } 3 \text { MOPs; total of } 34 \\
\text { MOPs performed either } 2 \text { weeks or } \\
4 \text { weeks before killing them } \\
\text { Location: from lingual } \\
\text { cortical plate in mandibular } \\
\text { furcation areas of third premolar, } \\
\text { fourth premolar, and first molar } \\
\text { Device: Propel device } \\
\text { Details: } 7 \text { mm depth }\end{array}$ & $2-4$ wks & $\begin{array}{l}\text { Effects of MOPs on bone are } \\
\text { transient }\end{array}$ \\
\hline $\begin{array}{l}\text { Kim et al }{ }^{30} \\
(2019)\end{array}$ & Animal study & $\begin{array}{l}24 \text { female } \\
\text { rabbits } \\
\text { Three experi- } \\
\text { mental groups } \\
\text { TC and IC with } \\
\text { flap } \\
\text { Flapless MPs and } \\
\text { a control }\end{array}$ & $\begin{array}{l}\text { Location: mesial to mandibular first } \\
\text { molar } \\
\text { Details: } \\
\text { TC group: } 1 \mathrm{~mm} \text { depth, } 3 \mathrm{~mm} \\
\text { width, } 5 \mathrm{~mm} \text { height bony defect } \\
\text { created after flap elevation using a } \\
1 \mathrm{~mm} \text { round bur } \\
\text { IC group: three indentations of } \\
1 \mathrm{~mm} \text { depth, } 1 \mathrm{~mm} \text { diameter, } \\
1 \mathrm{~mm} \text { apart using } 0.8 \mathrm{~mm} \text { round } \\
\text { bur after flap elevation } \\
\text { MOP group: two MOPs with a } \\
\text { diameter of } 1.4 \text { mm and depth } \\
\text { of } 3 \text { mm performed } 2 \text { mm apart } \\
\text { through gingiva with micro-screws }\end{array}$ & $4 \mathrm{wks}$ & $\begin{array}{l}\text { Significant difference } \\
\text { observed in intergroup tooth } \\
\text { movement } \\
\text { Tooth movement was seen } \\
\text { to be increased by } 46.5 \% \text { in } \\
\text { IC group, } 44.2 \% \text { in TC group, } \\
\text { and } 32 \% \text { in MP group. } \\
\text { Indentation corticotomy } \\
\text { group ( } 2.52 \mathrm{~mm}) \text { and TC } \\
\text { group ( } 2.48 \mathrm{~mm}) \text { showed } \\
\text { the largest amounts of tooth } \\
\text { movement } \\
\text { Micro-osteoperforation } \\
\text { group showed } 2.27 \text { mm } \\
\text { tooth movement and lastly } \\
\text { the control group had } \\
1.72 \text { mm tooth movement }\end{array}$ \\
\hline
\end{tabular}

Abbreviations: C, control; IC, indentation corticotomy; MOP, micro-osteoperforation; O, orthodontic force alone; OF, orthodontic force plus flap; OFP, orthodontic force plus flap plus perforations; TC, triangular corticotomy. 
and five chemokines showed a 1.7- to 2-fold increase. This favors the biological response of increased osteoclast recruitment due to the expression of cytokines and chemokines in increased amounts. The number of osteoclasts found within the group of rats given perforations were high and so was the amount of bone turnover. In addition, the effect caused by the perforations was not just limited locally but extended to the tooth-supporting structures of the adjacent teeth as well, maximizing the benefit and increasing the tooth movement rates. However, as much as the cytokine and chemokine levels were significantly increased, the effect did not extend to the contralateral side of the arch. Nonetheless, as it may be that the perforations can help with tooth movement significantly, it is nevertheless a double-edged sword, with the ability to cause a catastrophe on the alveolar bone and periodontal ligament if uncontrolled.

Alikhani et al $^{11}$ (refer to $\mathbf{- T a b l e} \mathbf{2}$ for details on the study conducted) followed through in 2013 with a human clinical trial in a randomized, single-blinded study on 20 adults divided into an experimental group and the other as the control group to see whether humans react similarly to MOPs as observed in the animal study. ${ }^{28}$ MOPs were delivered in the maxilla only, as the study was based on maxillary jaw analysis. They used subjects who had a Class II division 1 malocclusion and required the extractions of maxillary first premolars for the treatment. This type of malocclusion tends to exclude the effects of occlusion on the rate of tooth movement as a possible confounder. ${ }^{33,34,41}$ MOPs were administered either on the right or left side upon random assignation in a split-mouth study design. This has an advantage over using separate controls as it reduces the effects of different-subjects variability and availability of a limited sample.,3,7,35 MOPs were delivered on the experimental group 6 months after the extractions of maxillary first premolars to eradicate the confounding effect of inflammatory reactions activated due to the extraction site wound. A total of three MOPs was performed distal to the canines before retraction was commenced by using a disposable MOP device solely intended for this purpose by PROPEL Orthodontics (Ossining, NY). The levels of IL- $1 \alpha$ and IL- $1 \beta$ were significantly increased by 5.0 and 3.6 times, respectively, in the experimental group as compared with the control, enhancing the osteoclastic recruitment and activity. The amount of tooth movement in the experimental group on the side where MOPs were administered increased by a significant amount, 2.3-fold to be exact, when compared with the contralateral side of the experimental group and the control group as well. Gingival crevicular fluid samples showed a statistically significant difference between the expressions of cytokines and chemokines between the experimental and control groups. Patients also did not take any pain medications or experience any significant pain after the procedure was performed in both groups. ${ }^{14}$ In - Table 2, extraction of the information from the papers reported on MOPs outcomes done on the human.

Cheung et $\mathrm{al}^{29}$ evaluated the effectiveness of mini-implant facilitated MOPs for accelerating tooth movement, also investigating the effect on potential root resorption, if occurring. The study was conducted on six male Sprague-Dawley rats with split-mouth study design. A total of five MOPs at a depth of $1 \mathrm{~mm}$ were given by the help of a commercially available orthodontic mini-implant device; all of them on the left side of the maxilla mesially and palatally to the first molar. The right side of the jaw served as the control. Histological analysis of bone samples was also performed to evaluate the presence and numbers of osteoclasts defined as "multinucleated tartrate-resistant acid phosphatase+ cells" present on the surface of the bone samples. In this study as well, there was a 1.86-fold increase in the tooth movement rate in the experimental side as compared with the control side, very similar to another study conducted by Abdelhameed and Refai who reported a 1.6-fold increase in tooth movement on the MOP side in humans, ${ }^{17}$ including other studies. ${ }^{42}$ In agreement with the RAP, localized osteopenia was also observed apparent by the decreased bone volume density, bone mineral density, and bone volume fraction on the side where perforations were given, as refuted by another study as well. ${ }^{43}$ It was also found that the administration of MOPs did not induce any root resorption of the teeth involved. In addition, the MOP side showed on an average a $44 \%$ increase in the numbers of osteoclasts as compared with the contralateral side of the maxilla. The study also concluded with the fact that bone resorption was higher at the MOP side than bone formation, depicted by a more significant number of multinucleated osteoclasts present than at the control side, during the treatment duration. However, a more considerable amount of bone deposition was also occurring at the MOP side, which goes to show that bone turnover at the experimental side was increased. ${ }^{44}$

A distinctive advantage with the minimally invasive MOP placement is the repeatability of the procedure as opposed to the other invasive surgical assisted techniques. Due to this, a constant circulation of inflammatory chemokines and cytokines within the localized region of application can continue the rates of increased alveolar bone turnover. Multiple MOP procedures were performed in various studies to achieve this continued effect of cytokine release after giving MOPs, which showed a constant influence for a month on average. $3,9,17,31$

Cramer et $\mathrm{al}^{3}$ in their split-mouth animal study, however, demonstrated the application of eight MOPs at a depth of $7 \mathrm{~mm}$ on seven mature male beagle dogs in the jaw side randomly selected through computerized random number generation for the allocation of experimental and control sides. Contrary to the significant results in many studies, ${ }^{14,17,28,29}$ there was not an increase in tooth movement rates due to MOPs. They reported an average additional tooth movement of 0.05 to $0.27 \mathrm{~mm}$ on the experimental side compared with the control, which was statistically insignificant. This was in concordance with another study, ${ }^{41}$ which reported no effect on tooth movement rates in a split-mouth clinical trial on 32 patients at all time points in 3 months of the study duration. This could have been due to the small sample size, as mentioned by the authors. Also, the fact that as the tipping 


\begin{tabular}{|c|c|c|c|c|c|}
\hline 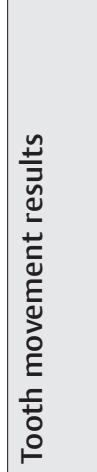 & 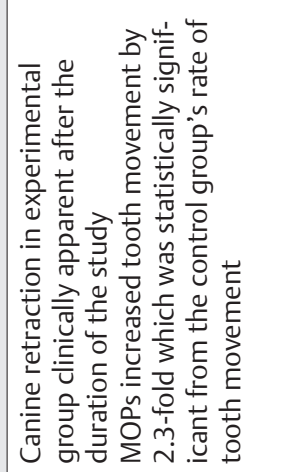 & 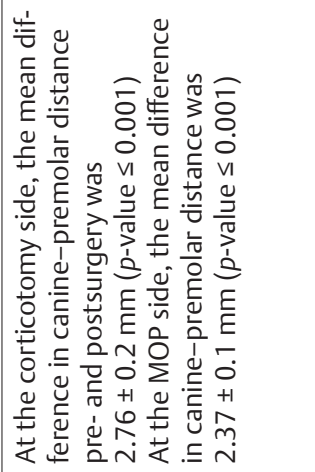 & 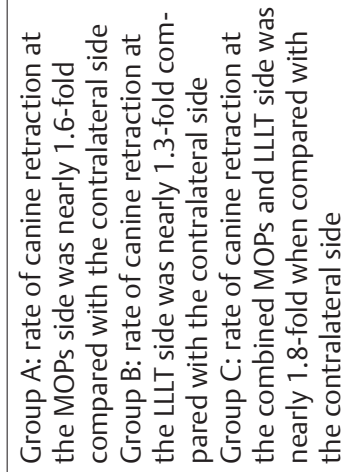 & 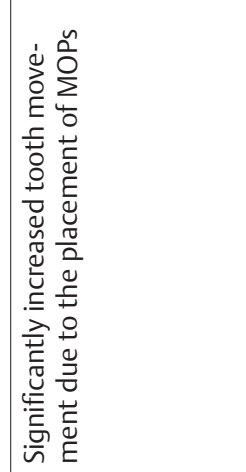 & 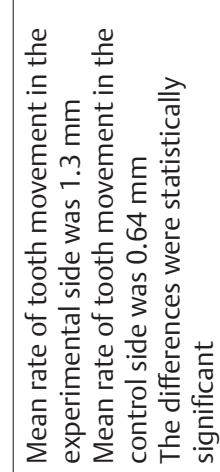 \\
\hline 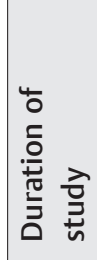 & $\begin{array}{l}\widetilde{\infty} \\
\stackrel{\infty}{\sim}\end{array}$ & 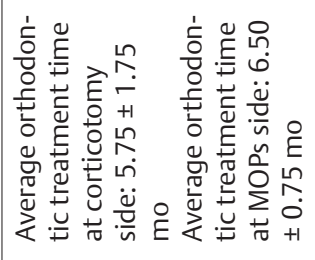 & $\stackrel{\circ}{\mathrm{E}}$ & 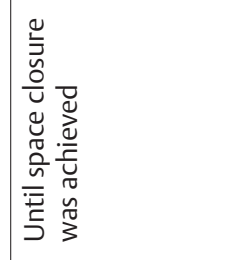 & $\begin{array}{l}\widetilde{\infty} \\
\stackrel{\infty}{N}\end{array}$ \\
\hline 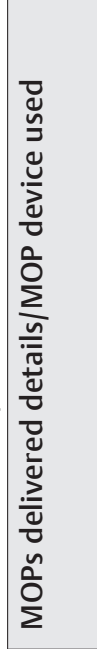 & 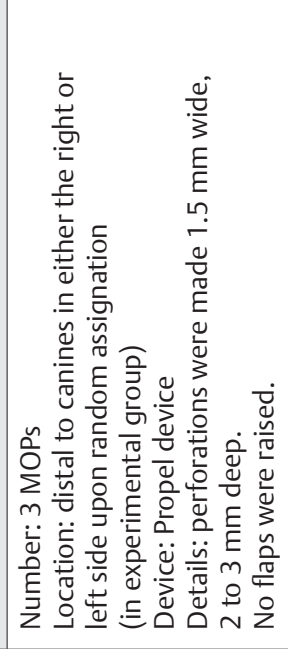 & 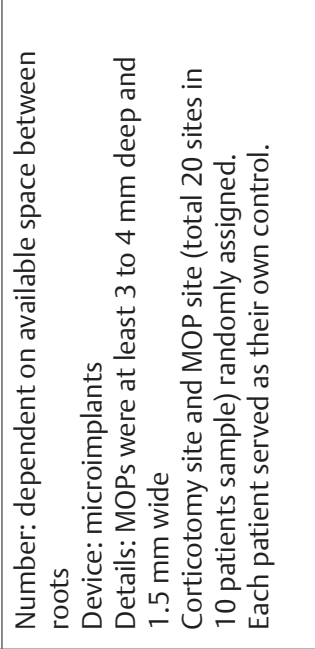 & 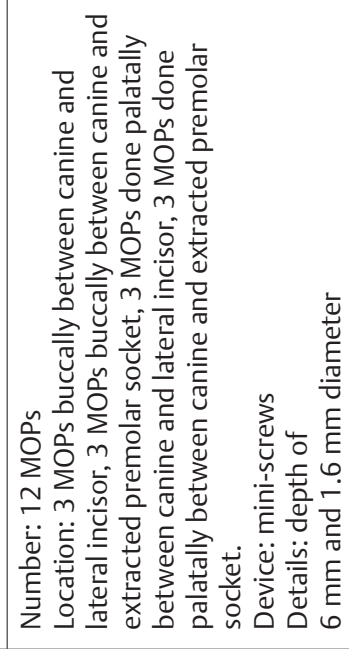 & 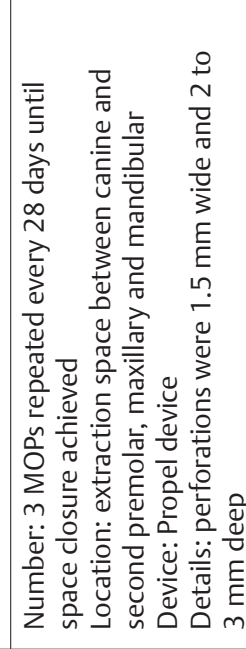 & 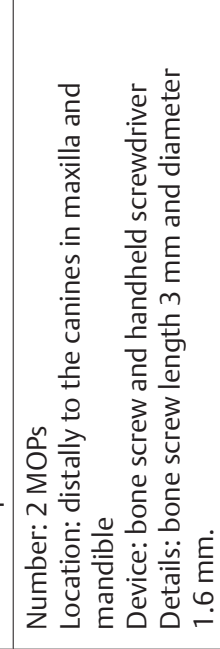 \\
\hline 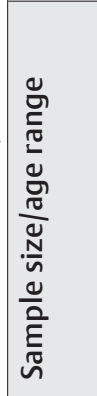 & 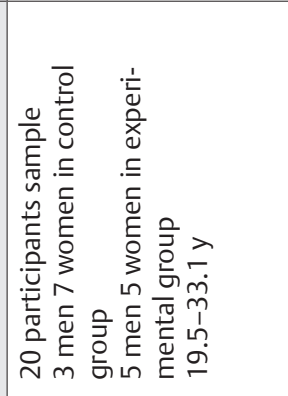 & 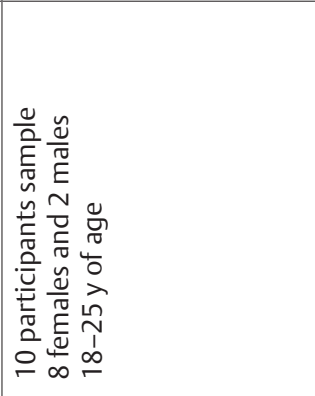 & 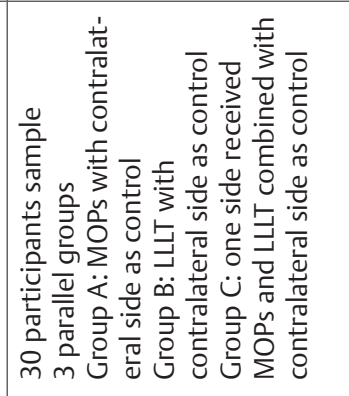 & 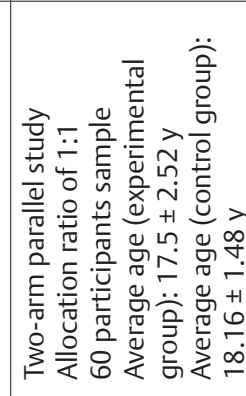 & 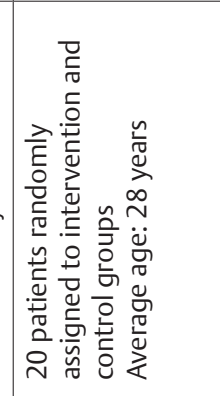 \\
\hline 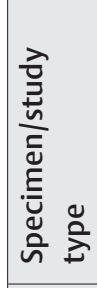 & 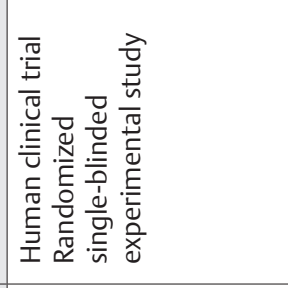 & 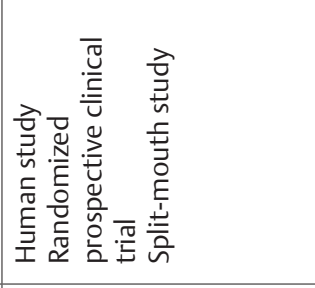 & 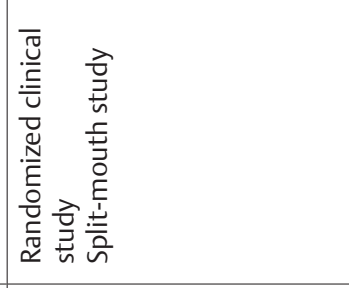 & 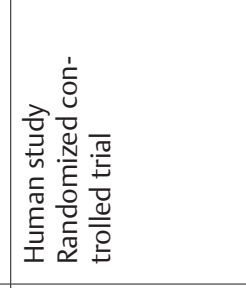 & 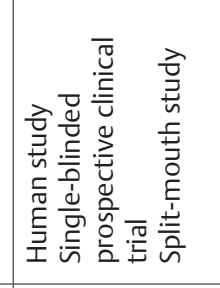 \\
\hline 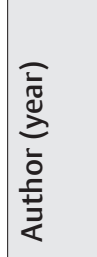 & 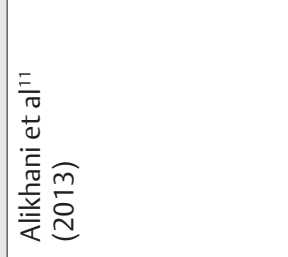 & 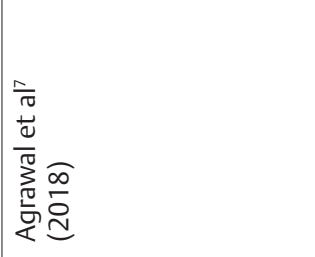 & 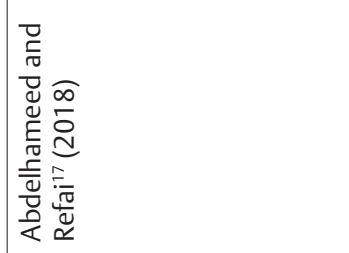 & 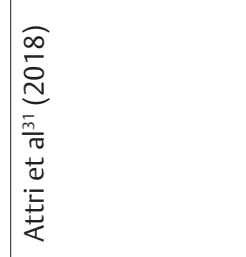 & 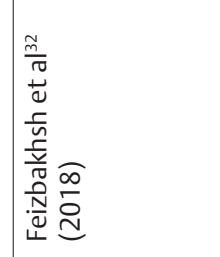 \\
\hline
\end{tabular}




\begin{tabular}{|c|c|c|c|c|c|c|}
\hline 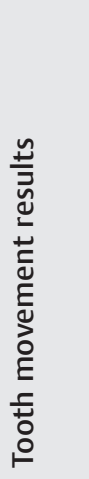 & 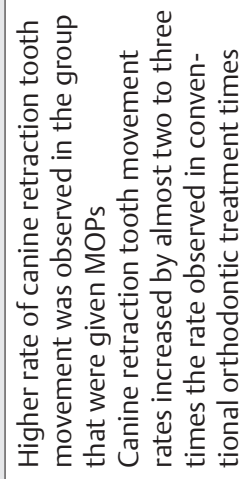 & 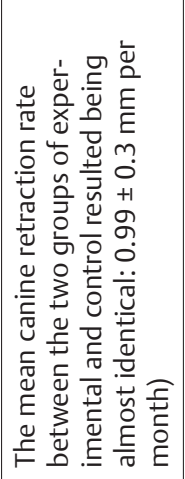 & 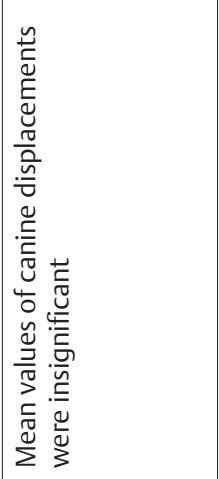 & 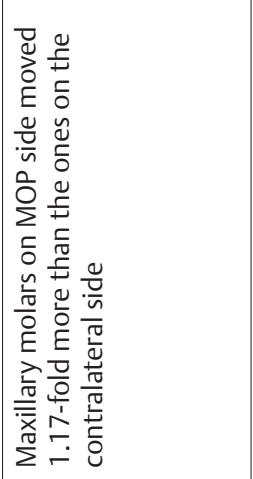 & 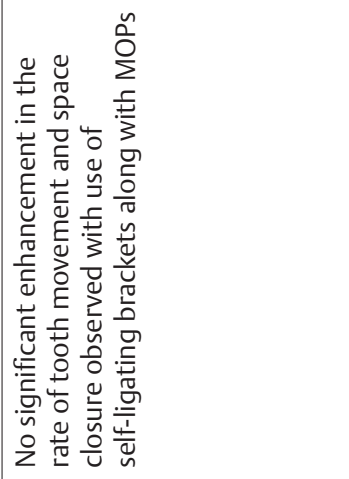 & 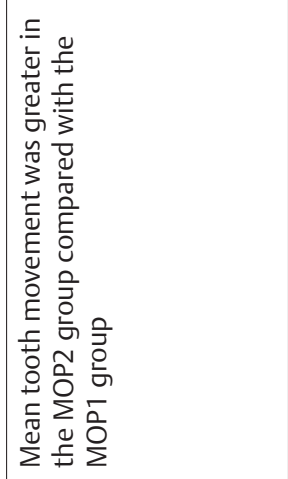 \\
\hline 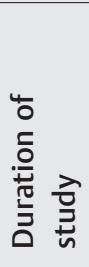 & $\begin{array}{l}\tilde{y} \\
\frac{\tilde{y}}{\tilde{y}} \\
\tilde{\sigma}\end{array}$ & $\stackrel{\circ}{E}$ & $\stackrel{\circ}{E}$ & $\begin{array}{l}\frac{\tilde{v}}{3} \\
\stackrel{N}{\simeq}\end{array}$ & 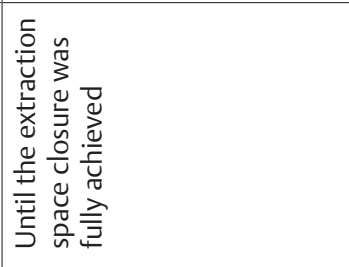 & $\stackrel{\stackrel{\circ}{E}}{m}$ \\
\hline 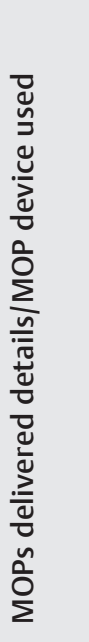 & 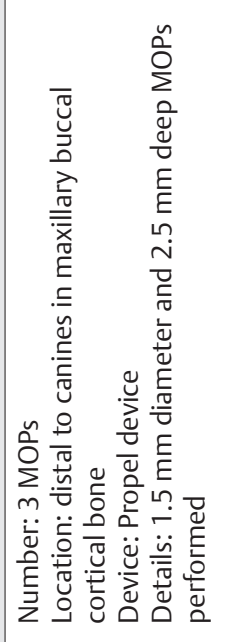 & 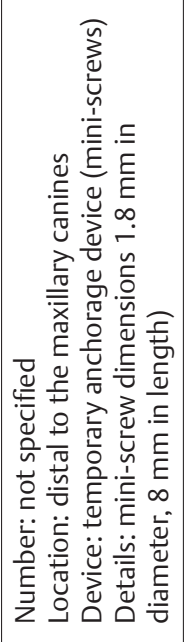 & 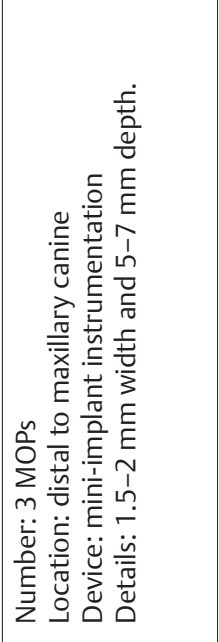 & 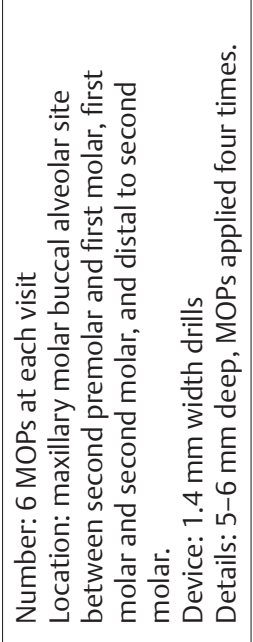 & 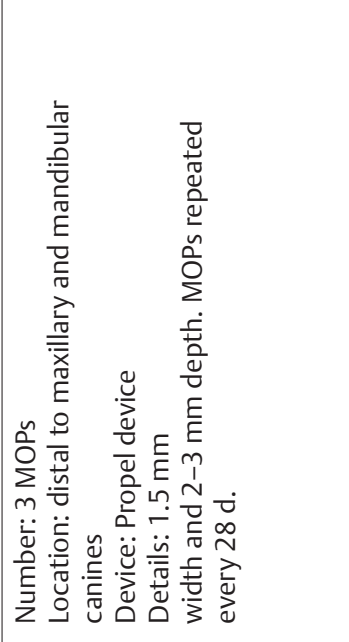 & 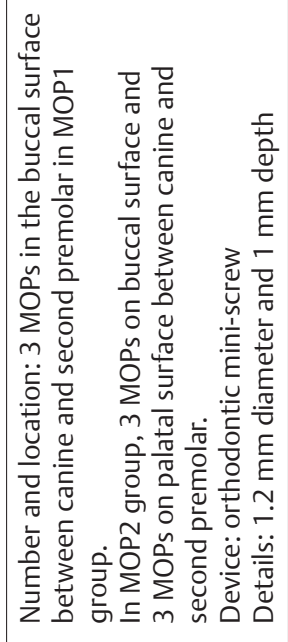 \\
\hline 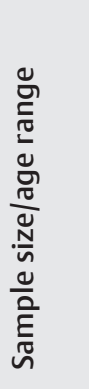 & 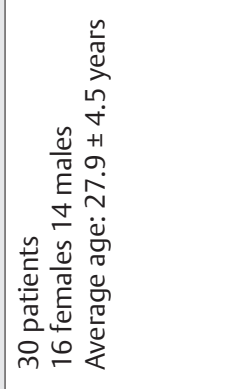 & 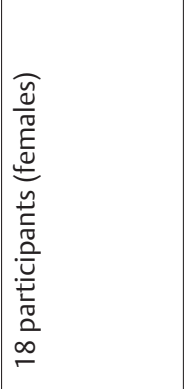 & 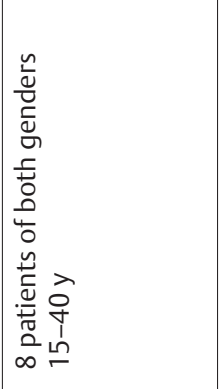 & 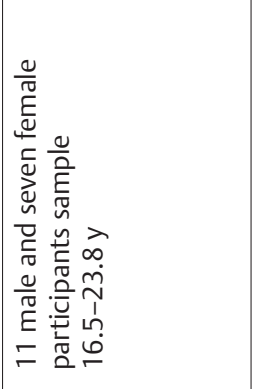 & 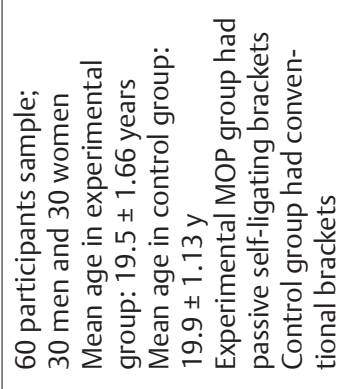 & 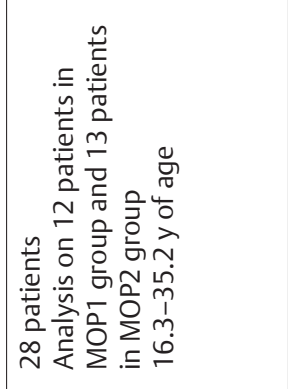 \\
\hline 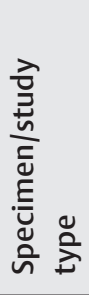 & 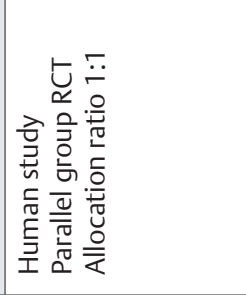 & 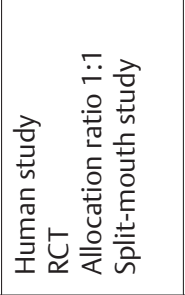 & 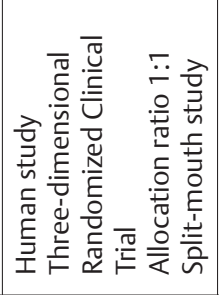 & 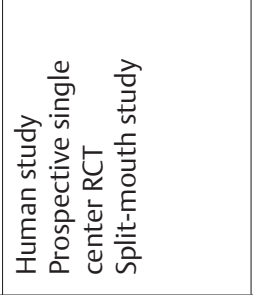 & 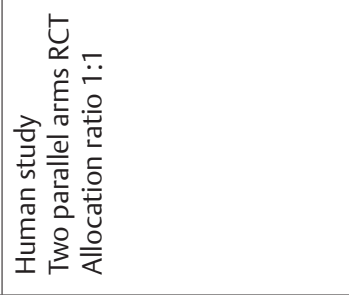 & 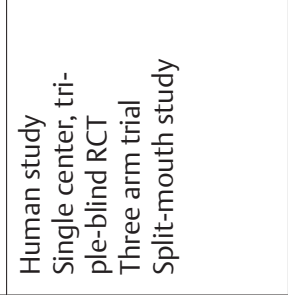 \\
\hline 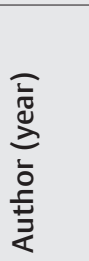 & 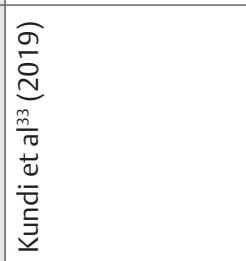 & 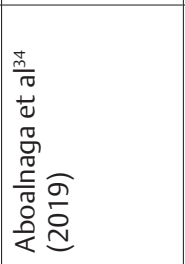 & 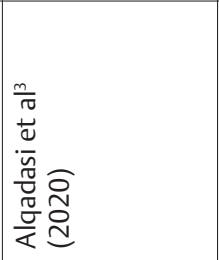 & 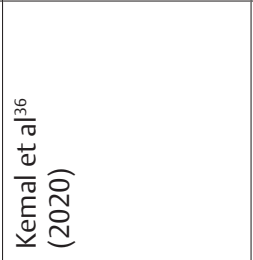 & 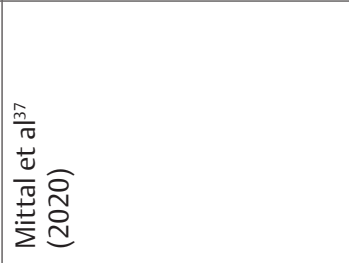 & 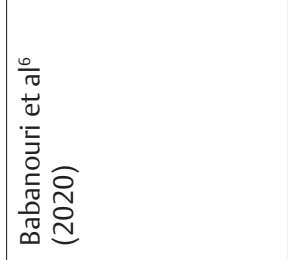 \\
\hline
\end{tabular}


of teeth was well controlled and only bodily movement was allowed in the study sample, this could have affected the results as well. ${ }^{3}$ Moreover, this raises another valid concern that both animals and humans have varying biological and metabolic responses to MOPs and subsequent orthodontic tooth movement, giving variegated results. ${ }^{36}$

A prospective randomized clinical trial, however, conducted by Feizbakhsh et al ${ }^{32}$ constituting the split-mouth design on humans, only two MOPs were performed, as opposed to the three number of perforations given in the studies conducted by Teixeira et $\mathrm{a}^{28}$ and Alikhani et al. ${ }^{11,14}$ The study demonstrated that there was a significant increase in tooth movement on the experimental side by 2.03 times with the placement of two MOPs, claiming the number as effective as giving three MOPs.

MOPs have been demonstrated to have a significantly positive increase in the acceleration of tooth movement as apparent by the literature. However, when compared with the corticotomy surgical procedure entailing the elevation of soft-tissue flaps, differing results have been obtained.

Kim et $\mathrm{al}^{30}$ conducted a study on rabbits comparing the effects of corticotomy and MOPs on orthodontic tooth movements between three experimental groups and one control group. The experimental groups consisted of one group on which triangular corticotomy (TC) was performed, one on which indentation corticotomy (IC) was performed, and the third on which MOPs were performed. The control group was given the conventional orthodontic treatment protocol. The more considerable amount of tooth movement rate was apparent in the corticotomy groups, with the IC group having a $46.5 \%$ increased tooth movement, the TC group having a $44.2 \%$ increased tooth movement, and the MOP group having a 32\% increased tooth movement, as compared with the control. Even though the intergroup differences in rates of tooth movement were not statistically significant. Nonetheless, it goes to show that corticotomies with raising soft tissue flaps create injuries of greater magnitude as compared with MOPs resulting in increased expressions of chemokines and cytokines necessary for the induction of bone remodelling. ${ }^{12}$ This similar conundrum could also have been a confounder in the study which was conducted by Teixeira et $\mathrm{al}^{28}$ who used MOPs along with soft tissue flaps, which thus resulted in increased tooth movement rates that were recorded. This masked the effects of the MOPs alone.

Despite several confounders that can alter the results associated with the administration of MOPs, such as the age of the patient, ${ }^{6,37}$ gender of the patient, ${ }^{34}$ short durations of study, ${ }^{4,932,36}$ limited sample size, ${ }^{3,35}$ type of tooth movement required during the treatment, occlusal interferences that can affect tooth movement rates, ${ }^{11}$ extraction sites not properly healed which could confound by causing an inflammatory reaction other than the one induced by MOP placement, inadequate oral hygiene, periodontal problems, usage of NSAIDS, habitual usage of a specific quadrant for chewing affecting the unequal distribution of occlusal forces, ${ }^{11}$ to mention a few. ${ }^{3,29,32,33}$

\section{Limitations}

No technique, till yet explored ${ }^{12}$ in the literature, is without its fair share of limitations. Many of the studies conducted on humans were randomized controlled clinical trials, as reviewed above. All of them adequately addressed the confounders and limitations of their respective studies. MOPs had an intended decreasing effect on the duration of tooth movement. The amount and magnitude of injury determines the rate of tooth movement. ${ }^{40}$ However, in the pioneer animal study ${ }^{28}$ which evaluated the effect of MOPs, it was implemented with the elevation of soft tissue flaps, which could have confounded the end-result completely due to the injury caused by MOPs.

The presence of limited sample sizes ${ }^{6,7,35}$ and shorter durations of the studies, ${ }^{6,736}$ can have a profound impact on the outcome impacted by the application of MOPs. The levels of chemo-attractants, chemokines, and cytokines were not evaluated by any other study reviewed except for two, one animal, ${ }^{28}$ and another human study. ${ }^{11}$

\section{Conclusion}

Various surgical techniques have shown promising results with regards to the acceleration of tooth movement. MOPs, however, are proving to be a minimally invasive, repeatable, relatively easily administered minor surgical procedure which can be done using normally available orthodontic appliances. Many animal studies and clinical trials have been done showing that MOPs favorably increase the osteoclast numbers by inducing an aseptic inflammatory reaction, thus increasing tooth movement rates. Several techniques have been outlined in the literature for the placement of MOPs as discussed in this review; the ideal and most effective method is yet to be evaluated. Patients have reported very mild and insignificant discomfort and pain after receiving MOPs as compared with those who undergo conventional orthodontic treatment procedures indicating that patient compliance is high with this procedure. Also, favorable is the reporting of insignificant external root resorption with this procedure which makes it suitable and convenient in comparison to corticotomies and osteotomies.

A way forward to further assess the effectiveness of MOPs and whether they actually accelerate the overall treatment time of orthodontic therapy includes conducting clinical trials for longer durations of time, preferably till the end of the treatment period completely. Also, the recruitment and follow-up of larger sample sizes is highly recommended.

\section{Conflict of Interest}

None declared.

\section{References}

1 Mavreas D, Athanasiou AE. Factors affecting the duration of orthodontic treatment: a systematic review. Eur J Orthod 2008;30(4):386-395 
2 Najeeb S, Siddiqui F, Qasim SB, Khurshid Z, Zohaib S, Zafar MS. Influence of uncontrolled diabetes mellitus on periodontal tissues during orthodontic tooth movement: A systematic review of animal studies. Prog Orthod 2017;18(1):1-7

3 Cramer CL, Campbell PM, Opperman LA, Tadlock LP, Buschang PH. Effects of micro-osteoperforations on tooth movement and bone in the beagle maxilla. Am J Orthod Dentofacial Orthop 2019;155(5):681-692

4 van Gemert LN, Campbell PM, Opperman LA, Buschang PH. Localizing the osseous boundaries of micro-osteoperforations. Am J Orthod Dentofacial Orthop 2019;155(6):779-790

5 Nimeri G, Kau CH, Abou-Kheir NS, Corona R. Acceleration of tooth movement during orthodontic treatment-a frontier in orthodontics. Prog Orthod 2013;14(1):42

6 Babanouri N, Ajami S, Salehi P. Effect of mini-screw-facilitated micro-osteoperforation on the rate of orthodontic tooth movement: A single-center, split-mouth, randomized, controlled trial. Prog Orthod 2020;21(1):7

7 Agrawal AA, Kolte AP, Kolte RA, Vaswani V, Shenoy U, Rathi P. Comparative CBCT analysis of the changes in buccal bone morphology after corticotomy and micro-osteoperforations assisted orthodontic treatment - Case series with a split mouth design. Saudi Dent J 2019;31(1):58-65

8 Frost HM. The regional acceleratory phenomenon: a review. Henry Ford Hosp Med J 1983;31(1):3-9

9 Sugimori T, Yamaguchi M, Shimizu M, et al. Microosteoperforations accelerate orthodontic tooth movement by stimulating periodontal ligament cell cycles. Am J Orthod Dentofacial Orthop 2018;154(6):788-796

10 Uematsu S, Mogi M, Deguchi T. Interleukin (IL)-1, IL-6, tumor necrosis factor-, epidermal growth factor, and2-microglobulin levels are elevated in gingival crevicular fluid during human orthodontic tooth movement. J Dent Res 1996;75(1):562-567

11 Alikhani M, Raptis M, Zoldan B, et al. Effect of micro-osteoperforations on the rate of tooth movement. Am J Orthod Dentofacial Orthop 2013;144(5):639-648 doi:10.1016/j.ajodo. 2013.06.017

12 Bolat E, Micro-osteoperforations. In: Aslan BI, Uzuner, FD, eds. Current Approaches in Orthodontics. London: IntechOpen; 2019 doi:10.5772/intechopen.81419

13 Zainal Ariffin SH, Yamamoto Z, Zainol Abidin IZ, Megat Abdul Wahab R, Zainal Ariffin Z. Cellular and molecular changes in orthodontic tooth movement. ScientificWorldjournal 2011;11:1788-1803

14 Alikhani M, Alansari S, Sangsuwon C, et al. Microosteoperforations: Minimally invasive accelerated tooth movement. Semin Orthod 2015;21:162-169

15 Krishnan V, Davidovitch Z. Cellular, molecular, and tissue-level reactions to orthodontic force. Am J Orthod Dentofacial Orthop 2006;129(4):469.e1-469.e32

16 Ren A, Lv T, Kang N, Zhao B, Chen Y, Bai D. Rapid orthodontic tooth movement aided by alveolar surgery in beagles. Am J Orthod Dentofacial Orthop 2007;131(2):160.e1-160.e10

17 Abdelhameed AN, Refai WMM. Evaluation of the effect of combined low energy laser application and micro-osteoperforations versus the effect of application of each technique separately on the rate of orthodontic tooth movement. Open Access Maced J Med Sci 2018;6(11):2180-2185

18 Nishimura M, Chiba M, Ohashi T, et al. Periodontal tissue activation by vibration: intermittent stimulation by resonance vibration accelerates experimental tooth movement in rats. Am J Orthod Dentofacial Orthop 2008;133(4):572-583

19 Bartzela T, Türp JC, Motschall E, Maltha JC. Medication effects on the rate of orthodontic tooth movement: A systematic literature review. Am J Orthod Dentofacial Orthop 2009;135(1):16-26
20 Shahabee M, Shafaee H, Abtahi M, Rangrazi A, Bardideh E. Effect of micro-osteoperforation on the rate of orthodontic tooth movement-a systematic review and a meta-analysis. Eur J Orthod 2019;doi: 10.1093/ejo/cjz049

21 Alfawal AMH, Hajeer MY, Ajaj MA, Hamadah O, Brad B. Effectiveness of minimally invasive surgical procedures in the acceleration of tooth movement: A systematic review and meta-analysis. Prog Orthod 2016;17(1):33

22 Köle H. Surgical operations on the alveolar ridge to correct occlusal abnormalities. Oral Surg Oral Med Oral Pathol 1959;12(5):515-529

23 Suya H. Corticotomy in orthodontics. In: Hosl E., Baldauf A., eds. Mechanical and Biological Basis in Orthodontic Therapy. Huthig Buch Verlag; Heidelberg, Germany; 1991: 207-226

24 Wilcko MT, Wilcko WM, Bissada NF. An evidence-based analysis of periodontally accelerated orthodontic and osteogenic techniques: A synthesis of scientific perspectives. Semin Orthod 2008;14(4):305-316

25 Park YG, Kang SG, Kim SI. Accelerated tooth movement by corticision as an osseous orthodontic paradigm. Kinki Tokai Kyosei Shika Gakkai Gakujyutsu Taikai, Sokai 2006;28:6

26 Dibart S, Keser EI, Piezocision TM minimally invasive periodontally accelerated orthodontic tooth movement procedure. In: Brugnami F, Caiazzo A, eds. Orthodontically Driven Corticotomy: Tissue Engineering to Enhance Orthodontic and Multidisciplinary Treatment. Vol 30. Hoboken, NJ: Wiley Blackwell; 2014: 119-144

27 Abbas NH, Sabet NE, Hassan IT. Evaluation of corticotomy-facilitated orthodontics and piezocision in rapid canine retraction.AmJOrthod Dentofacial Orthop 2016;149(4):473-480

28 Teixeira CC, Khoo E, Tran J, et al. Cytokine expression and accelerated tooth movement. J Dent Res 2010;89(10):1135-1141

29 Cheung T, Park J, Lee D, et al. Ability of mini-implant-facilitated micro-osteoperforations to accelerate tooth movement in rats. Am J Orthod Dentofacial Orthop 2016;150(6):958-967

30 Kim J, Kook YA, Bayome M, et al. Comparison of tooth movement and biological response in corticotomy and micro-osteoperforation in rabbits. Korean J Orthod 2019;49(4):205-213

31 Attri S, Mittal R, Batra P, et al. Comparison of rate of tooth movement and pain perception during accelerated tooth movement associated with conventional fixed appliances with micro-osteoperforations - a randomised controlled trial. J Orthod 2018;45(4):225-233

32 Feizbakhsh M, Zandian D, Heidarpour M, Farhad SZ, Fallahi HR. The use of micro-osteoperforation concept for accelerating differential tooth movement. J World Fed Orthod 2018;7(2):56-60

33 Kundi I, Alam MK, Shaheed S. Micro-osteo perforation effects as an intervention on canine retraction. Saudi Dent J 2020;32(1):15-20

34 Aboalnaga AA, Salah Fayed MM, El-Ashmawi NA, Soliman SA. Effect of micro-osteoperforation on the rate of canine retraction: a split-mouth randomized controlled trial. Prog Orthod 2019;20(1):21

35 Alqadasi B, Aldhorae K, Halboub E, et al. The effectiveness of micro-osteoperforations during canine retraction: A three-dimensional randomized clinical trial. J Int Soc Prev Community Dent 2019;9(6):637-645

36 Gulduren K, Tumer H, Oz U. Effects of micro-osteoperforations on intraoral miniscrew anchored maxillary molar distalization: a randomized clinical trial. J Orofac Orthop 2020;81(2):126-141

37 Mittal R, Attri S, Batra P, Sonar S, Sharma K, Raghavan S. Comparison of orthodontic space closure using micro-osteoperforation and passive self-ligating appliances or 
conventional fixed appliances. Angle Orthod 2020;90(5):634639 doi:10.2319/111119-712.1

38 Nicozisis JL. Accelerated orthodontics through micro-osteoperforation. Orthod Pract 2014;4(3):56-57

39 Henneman S, Von den Hoff JW, Maltha JC. Mechanobiology of tooth movement. Eur J Orthod 2008;30(3):299-306

40 Sangsuwon C, Alansari S, Lee, YB, Nervina, J, Alikhani, M, Step-by-step guide for performing micro-osteoperforations. In: Alikhani M, ed Clinical Guide to Accelerated Orthodontics. New York City, NY: Springer International Publishing; 2017 99-116

41 Alkebsi A, Al-Maaitah E, Al-Shorman H. Abu Alhaija E. Three-dimensional assessment of the effect of micro-osteoperforations on the rate of tooth movement during canine retraction in adults with Class II malocclusion: A randomized controlled clinical trial. Am J Orthod Dentofacial Orthop 2018;153(6):771-785

42 Baloul SS, Gerstenfeld LC, Morgan EF, Carvalho RS, Van Dyke TE, Kantarci A. Mechanism of action and morphologic changes in the alveolar bone in response to selective alveolar decortication-facilitated tooth movement. Am J Orthod Dentofacial Orthop 2011;139(4(Suppl):S83-S101

43 Chang HW, Huang HL, Yu JH, Hsu JT, Li YF, Wu YF. Effects of orthodontic tooth movement on alveolar bone density. Clin Oral Investig 2012;16(3):679-688

44 Ferguson DJ, Vaid NR, Wilcko MT. Assessing accelerated tooth movement techniques on their own catabolic merits: A review. J World Fed Orthod 2018;7(4):122-127 